\title{
4 Types of diagnoses in Papyrus Ebers and Smith
}

\author{
Susanne Radestock
}

\section{Introduction: the chronological classification of the medical papyri Ebers and Smith}

Egyptian medical texts on papyrus and ostraca have been preserved from the time of the Middle Kingdom (1940-1640 BCE) until the Graeco-Roman and Byzantine Period (332-641 CE). ${ }^{1}$ The two hieratic papyri Ebers ${ }^{2}$ and $\mathrm{Smith}^{3}$ date to the New Kingdom (1550-1070 BCE), more precisely to the beginning of the New Kingdom (ca. 1550 BCE). The Papyrus Ebers, kept at the library of the University of Leipzig/Albertina, ${ }^{4}$ is a compendium of diverse medical prescriptions and instructive texts - e.g. for skin, eye or inner ailments - containing in all almost 880 individual texts on its recto (1.1-110.9). Interestingly, on the back of the first column, there is a 13-line calendric note from the ninth regnal year of the king Amenhotep I. ${ }^{5}$ The papyrus' length is approximately $18 \mathrm{~m}$ and its height is $30 \mathrm{~cm}$.

The repository of Papyrus Edwin Smith is in the New York Academy of Medicine. Its recto contains 48 texts concerning diverse injuries of different degrees of severity (1.1-17.19), which is why it is called 'Wundenbuch' in German (the literal English equivalent would be 'book of wounds', although the academy calls it the 'Surgical Papyrus'). ${ }^{6}$ Its verso contains spells against epidemics (18.1-20.12) and some instructional texts and medical prescriptions (20.13-22.14). The length amounts to $4.7 \mathrm{~m}$, the height to $32 \mathrm{~cm}$.

\section{The structure of instructive medical texts}

The usual textual structure of an Egyptian medical instructive text is as follows. ${ }^{7}$ The majority of the texts start with a title, followed by the examination (with the semeiotic passage); the diagnosis, followed by (in some cases) the verdict, of which there are three variants; and finishing with the recommended therapy. Glosses detailed explanations of single words, phrases or sentences - can conclude the text, especially in the case of the Papyrus Edwin Smith. Later this structure will be shown in the text examples.

\section{Variants of verdicts}

Verdictsarecatamnesticvestiges(providingpieces ofinformationonthedevelopment of the patient following the onset of an illness) and, besides the diagnostic passages, 
another sign for the casuistic base of the texts. ${ }^{8}$ Following the diagnostic passages, the verdicts are a typical feature, especially of the Papyrus Smith and of the 'Geschwulstbuch' ('book of swellings') in the Papyrus Ebers. There are three variants:

- the positive verdict: $m h r j r j=j$ - 'an ailment which I will treat'

- the ambivalent verdict: $m h r^{c} h \zeta=j h n^{c}-$ 'an ailment with which I will contend'

- the negative verdict: $m h r n j r j . w n j$ - 'an ailment not to be treated'

The latter verdict is most probably verbalised in the context of infaust cases. Mostly it is recommended not to apply any treatment; smaller, soothing measures are sometimes recommended. The varying reference in the verdict's frame is remarkable: while the positive and ambivalent verdicts make use of the first person singular, negative verdicts are given in an impersonal passive form.

\section{Diagnostic passages and types of diagnoses}

The diagnosis plays an essential role within the instructional textual structure and is a central aspect of the Egyptian medical system in general. Conclusively presupposed are experiences with 'cases of XY'. ${ }^{9}$ That is to say, all the instructional texts are based on case histories, though they are not veritable case histories. ${ }^{10}$

There exist five main types of diagnoses, metalinguistically embedded in the textual structure by the set phrase 'then you must say thereto' $(\underline{d} d . h r=k r=s)$. The first type of diagnosis, naming of a disease, is exceptional and occurs only in one text of the corpus under consideration. The second group of diagnoses, paraphrases of states of suffering, is the biggest one and found in the majority of the texts; it can be divided into several subgroups. Apart from these, a third and fourth group can be differentiated, which consist of a type of injury with localisation, and an unspecified lesion with localisation. Last, there is another, rather rare type of diagnostic passage, namely the lack of any diagnosis. ${ }^{11}$

The different groups of diagnosis can be illustrated with the following text extracts: ${ }^{12}$

1 naming of a disease (name):

Eb 191 w $\underline{3} d p w$ - 'it is the green illness' (within the semeiotic passage)

2 paraphrases describing states of suffering, forming the following subgroups:

a pathological states of anatomical entities:

Eb 188: sp pw $n$ mjs.t - 'it is a morbid state of the liver'

Eb 831: 3hㄷ.t $p w h r j d . t=s$ - 'it is a scratch on her womb'

b pathological state of a physiological entity:

Eb 193: shn $p w n$ hs $n t s t=f-$ 'it is a conglomerate/agglomeration of faeces that has not yet solidified' 
c pathophysiological occurrences:

Eb 190: sts. $w$ pw $h r \underline{d r w w}=f-$ 'it is the raisings of his cough'

d particular state or quality of a pathological entity (especially of endogenous nature), sometimes with localisation:

Eb 192: shw3.w pw $n w$ st.t $=f-$ 'it is the products of putrefaction of his matter of mucus'

Eb 871: ${ }^{c} 3 . t p w n t w h d w m t p . w^{c} . w j=f j-$ 'it is an ${ }^{c} 3 . t$-'swelling of matter of pain of his arms'

e pathological entity as such, sometimes with localisation:

Eb 856f: st.t pw - 'it is the matter of mucus'

f unspecific metalinguistic reference to the disease as such with localisation:

Eb 865: $3 h \underline{h r w-t} 3 w$ m $h r j n \underline{h} . t=f-$ 'the suffering is in a state of deficient air (?) in the lower part of his belly'

g demonic influence (exogenous genesis):

Eb 191: ' $k . t m$ r3 $p w$ mwt pw hns $n=f$ - 'it is something that has entered through his mouth, it is death that approaches him'

3 type of injury with localisation:

Sm 4: hrj wbnw $n k f . t m t p=f^{c} r n k s p \check{s} n \underline{d n n} . t=f-$ 'one with a gaping wound at his head that reaches as far as the bone, his skull is cleft'

Sm 42: hrj nrw.t $m$ hnn.w nw k̉b.t=f - 'one with a bruise at the ribs of his chest'

Within this group we have another peculiarity, the 'core diagnosis' and semeiotic-like specification. For instance, Sm 24 presents the core diagnosis $h r j h s b{ }^{c}$ cr.t $=f$ - 'one with a fracture in his mandible', adding the specification $s \underline{d}$ wbnw $h r=f$ wib $3 b . n=f s p \check{s} m m=f \underline{h r}=s-$ 'a wound has opened on it, the discharge (?) has stopped to seep (?), he is febrile as a result of this'.

4 unspecified lesion with localisation:

Sm 10: $w b n w m$ jnh $=f-$ '(one with) a wound in his eyebrow'

5 no diagnosis: e.g. Eb $617,870,877$

\section{Selected text passages from Papyrus Ebers and Smith}

In the following, I will discuss nine texts illustrating the different identified types of diagnoses (the type of diagnosis is given at the beginning in brackets, followed by transliteration, ${ }^{13}$ translation and a short comment). ${ }^{14}$ 


\section{Susanne Radestock}

\section{Eb 191 (37.10-17) = Eb 194: naming of a disease and demonic influence}

The first of the nine text examples discussed here in detail contains a debatable naming of a disease (name) within the semeiotic passage; it is part of a larger text group of 21 individual texts, the so-called 'Magenbuch' ('book of the stomach', Eb 188 (36.4-17) to Eb 207 (42.8-43.2)):

$j r \underline{h} 3 j=k s$ hr $m n r^{3}-j b=f$ 'If you examine a man who is suffering from his stomach,

${ }^{37.11} j w=f m n=f g 3 b=f m n d=f$ he is suffering from his arm, his chest, gs $n r j-j b=f$ at the side of his stomach,

$j w \underline{d} d . t w r=f w 3 \underline{d} p w$ it is said thereto: it is the green sickness (?).

$37.12 \underline{d} d . h r=k r=s$ Then you should say thereto:

ck.t $m r^{3} p w$ It is something that has entered through his mouth, $m w t p w$ hns $n=f$ It is death that approaches him.

(instructions for the preparation of a potion follow)

${ }^{37.15} r \underline{d j} . \underline{h} r=k \underline{d} r . t=k \hat{h} r=f$ Then you should put your hand on him,

$k^{c} h . t j r n d m g 3 b \breve{s} w \boldsymbol{m} j h$ while it is flexed, until the arm gets better, while

being free from suffering.

$\underline{d} d . h r=k$ Then you should say thereto:

${ }^{37.16} j w$ h hj.t pn h3j $r \mathrm{k}^{3} \mathrm{~b} \mathrm{~m}^{\mathrm{C}} \mathrm{r}$ phwj.t This suffering has descended to the rectum, to the anus, $n w h m=j^{37,17} \operatorname{sp} r s j$ I do not at all repeat the remedy'.

The semeiotic passage describes a patient suffering from an afflicted arm, abdomen and thorax (it is not entirely clear whether only its frontal region is affected, which is suggested by the term $m n \underline{d}$ (chest). The term $w 3 \underline{d}$ seems colloquial but could just as well derive from an environment that uses a technical terminology. All the translations that have been suggested - ' $w \underline{j} \underline{d}$-illness', ${ }^{15}$ ' $w 3 d$-Krankheit', ${ }^{16}$ 'Grünfärbung' ${ }^{17}$ and 'maladie verte'18 - are speculative, as is the one given here. Possibly the term points to the pale complexion in the case of nausea. Be that as it may be, it is not certain at all whether $w \underline{d} \underline{d}$ refers to its semantics in the sense of 'the colour green' ${ }^{19}$ And something else is unclear: does it refer to a disease name - as the translations by Ebbell, von Deines, Grapow, Westendorf and Bardinet just cited sugges $\mathrm{t}^{20}$ - or to a symptom? Concerning the latter, Hannig renders it as '*grüne Gesichtsfarbe (d. Patienten)'. ${ }^{21}$ The semeiotic passage ends with 37.11: $j w \underline{d d}$.tw $r=f w 3 \underline{d} p w$ is part of the semeiotics; 'it is said thereto' is a metalinguistic introduction to the following term $w 3 \underline{d}$. 'While it is flexed' $\left(k^{c} h . t j\right)$ refers to the hand of the treating person.

The following diagnosis given in 37.12 concerns $c^{c} \mathrm{~m} \mathrm{rwtj}{ }^{22}$ - 'to enter from the outside' - a demon that penetrates the body. This phenomenon is explicated at best in the gloss D Sm 8 (4.16-17), where we learn that it is 'not the entering of something that his flesh has created' $-\ldots n k m 3 t h^{c} w=f$. In this case, the demon has entered through the mouth; Westendorf interprets $r^{3}$ as an incantation..$^{23}$ The situation described here is potentially life-threatening, as the phrase $m w t p w$ hns 
$n=f$, 'it is death that approaches him', shows. It can be compared to the effects of $t 3 w n m w t$, 'the breath of death' ${ }^{24}$

\section{Eb 193 (38.3-10) pathological state of a physiological entity}

$j r \underline{h} 3 j=k s^{38.4} \underline{h} r \check{s}^{c} n r^{3}-j b=f^{\prime}$ If you examine a man with a constipation of his stomach,

$r d j . h r=k \underline{d} r . t=k h r=f$ then you should put your hand on him, $g m m=k$ hjj. $t=f^{38.5}$ swmt. $w=f 3 w r$ and you find his illness/symptom of illness while his thickenings are shivering spd.tj $\underline{d} b 3 . w h r=f$ while the fingertips are on him, $\underline{d} d . h r=k r=f$ then you should say thereto: shn $p w n$ hs It is a conglomerate of faeces ${ }^{38.6} n$ ts. $t=f$ that has not (yet) solidified'.

The passage is followed by instructions for the preparation of special foods in the course of a special diet which the patient should observe, and closes with the statement:

${ }^{38.10} r \operatorname{sn} b=f h r-{ }^{c} w j$ 'so that he convalesces immediately'.

The topic of this second example from the 'Magenbuch' is maldigestion, specified by $\check{s} n^{c}$ - constipation'. The patient is being palpated, at first with the flat hand, later with the fingertips. swmt. $w=f$ 'his thickenings' could refer on the one hand to an inflated abdomen, which is present for example in meteorism, which can be accompanied by maldigestion. On the other hand, the term may refer to the chymus, located at different loci/places of the alimentary tract. ${ }^{25}$ The 'thickenings' (swmt.w) 'shiver' ( $3 w r)$, which might be the cause of motility disorder, more precisely abnormal vermicular motility (intestinal peristalsis). Westendorf translates 'seine Krankheitserscheinung . . . verdickt; seine (des Magens) Gefäße zittern ... ${ }^{26}$ The diagnosis indirectly refers again to these thickenings, which are identified as digesta ( $\operatorname{shn} n h \mathrm{~h} s$ 'conglomerate of faeces'). ${ }^{27}$ Their present state is $n$ ts.t-'not (yet) solidified'. The reason for putting 'yet' in brackets is that this word's usage gives an important nuance: it implies that $t$ s.t exists in a temporary state of abnormal consistency and that the normal consistency has yet to be reached. Not to use this adverb has another effect on the semantics of the whole phrase, implying that normal consistency cannot be obtained.

\section{Eb 617 (78.6-10) = H 174: no diagnosis}

$j r g m j=k \underline{d} b^{c} s 3 h r^{3-78.7} p w m r=s n$ 'If you find a finger or a toe, when they are aching,

$p h r m w h{ }^{3}=s n$ (and) there is water circulating behind them,

$\underline{d} \boldsymbol{w} \boldsymbol{s t} \mathbf{j}=\boldsymbol{s n}$ (and) their odour is bad,

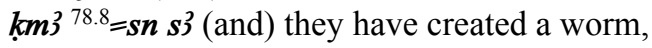




\section{Susanne Radestock}

$\underline{d} d . h r=k r=s$ then you should say thereto:

$\boldsymbol{m} \boldsymbol{j} \boldsymbol{j} \boldsymbol{j} \boldsymbol{j} \boldsymbol{j}$ (It is) an ailment which I will treat.

$j r j . h r=k n=f s p . w n w^{78.9} s m 3 s p$ Then you should make for him a remedy for the killing of the worm'.

(followed by ingredients, to be used in a bandage)

The semeiotic passage describes this case of a liquid located under the fingernails, literally 'behind them' $(h 3=s n)$. Bardinet considers this as the description of serum. ${ }^{28}$ The exudate is probably rather serous-purulent or even sanious because of the reported bad smell. The word $s 3$ is a veritable metaphor here, in other words, it is not worms that are meant, as some translators consider, ${ }^{29}$ but rather 'wurmähnliche Gerinnsel aus Eiter bzw. Wasser' ('worm-like curd from pus or water'), as Westendorf paraphrases..$^{30} \mathrm{~A}$ diagnosis in the narrower sense is not part of this text. Although the set phrase 'then you should say thereto' usually introduces the diagnosis, here it only contains a positive verdict and no description of a disease or description of a pathological state.

\section{Eb 831 (96.16-20): pathological state of an anatomical entity}

jr $h 3 j=k$ s.t $p 3 n=s^{96.17} h 3 j . t j h . t ~ m j ~ m w$ 'If you examine a woman who has evacuated something like water,

phwj jrj mj snf $k f n$ the deposit of which is like curdled blood, $d d . h r=k r=s$ then you should say thereto:

$96.18{ }^{2} h^{c} . t p w$ hr jd.t=s It is a scratch on her womb'.

The diagnosis is followed by instructions for the preparation of a remedy to be put on a bandage and to be applied for four days vaginally.

The gynaecological text probably thematises an examination after the actual occurrence of the discharge has ceased. An acute discharge is nonetheless possible, maybe in the context of a trauma - albeit the text says nothing regarding this, as it is silent on the duration of the discharge or its quantity. The text is clear about its consistency, which is watery and emerges like 'curdled blood' (snf $k f n$ ). There are controversies whether the two statements describe a temporal sequence or two interlinked observations on the consistency of the discharge. Ebbell tends to the view of a discharge that passes within a rather short time and that its 'deposit ... is like curdled blood'; ${ }^{31}$ similarly Bardinet: 'des choses comme de l'eau au fond de laquelle (il y aurait) comme du sang cuit' ${ }^{32}$ Von Deines, Grapow and Westendorf, however, see a temporal sequence. ${ }^{33}$ The main topic might be a puerperal or menstrual disorder or something entirely independent. The diagnosis, if not a metaphor, presents a pathogenic entity, $3 h^{c} . t^{34}-$ in this case thought to be something that is located on the uterus' surface, provoking (a) discharge. ${ }^{35}$

\section{Eb 856f (103.11-13) = Bln 163f: pathological entity as such}

$j w \boldsymbol{m} t 2 j \boldsymbol{m}=\boldsymbol{f} \boldsymbol{n} \boldsymbol{g} \boldsymbol{3} \boldsymbol{b}=\boldsymbol{f}^{\prime}$ There are two vessels in him to his upper arm. jr $m n={ }^{103.12} f k^{c} h=f d{ }^{3} d b^{c} . w=f$ If he is ill in his shoulder and his fingers shiver 
$\underline{d} d . h r=k r=s$ then you should say thereto:

st.t $p w$ It is matter of mucus'.

Instructions for the preparation of an emetic and of a bandage to be applied on his fingers follow.

This example is part of the so-called zweites Gefäßbuch ('second book of the vessels'; Eb 856a (103.1-2) to Eb 856h (103.16-18)), which presents primarily anatomical information. The text gives details concerning the vessels and the relevant anatomical area, the area of the upper arm. The observed affliction of the shoulder is accompanied by tremor of the fingers, for which no qualitative explanations are available. Dawson thinks about a case of 'paralysis agitans', ${ }^{36}$ which is the outdated designation for Parkinson's disease. The diagnosis, in this case also the aetiology, is precise: st.t-'Schleimstoffe' ${ }^{37}$ ('matter of mucus') are the cause.

\section{Eb 871 (107.16-108.3): particular state or quality of a pathological entity}

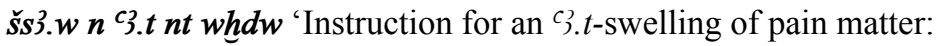

$j r^{107.17} w p j=k^{c}$ 3.t $n t w h d w m t p . w^{c} . w j=f j$ If you assess an ${ }^{c}$ 3.t-swelling of pain matter in the tips of his arms,

$g m m=k s j k m 3 . n=s m w$ and you find that it has produced water, $j w=s r w^{107.18} \underline{d} . t j \underline{h} r \underline{d} b^{c} . w=k m n . t j$ it is solid under your fingers, staying, $j w=s$ gnn.tj $n$ js wr.t it is soft, but not very,

$\underline{d} d . j n=k r=s$ then you must say thereto:

107.19 c3.t pw $n t$ whdw $m$ tp. $w^{c} . w j=f j$ It is an ${ }^{c}$ 3.t-swelling of pain matter in the

tips of his two arms,

$m h r j r j=j$ an ailment which I will treat.

$j r j . h r=k n=s \underline{d w}{ }^{c}{ }^{c}$ Then you should perform a treatment by knife for it, ${ }^{107.20}$ s3w.tj $r$ $m t$ Be careful with the vessel!

$j w$ jh.t pr jm=s mj $m w n w$ kmj.t The things that came out of it, are like water of gum, wnn ${ }^{c} r f 108.1 . n=s$ tm3w.t it has enclosed a pouch, $j m j=k$ rdj spj jh.t jm $=s j m j=s w d b$ you should not allow that things stay inside of it, so that it does not return.

$s r w h=k s j^{108.2} \mathrm{mj} s r w h$ wbnw $m^{c}$.t nb.t $n t s$ Then you should treat it according to the treatment of a wound at any body site of the man, $s \underline{t} 3 m s n \underline{d} m m t . w$ let it coat itself, alleviation of the vessels. $j w={ }^{108.3} s \check{s} f=s m-h t d r=s$ It swells after it has been removed, jn jnw.t jrr $s$ r It is the jnw.t-occurrences that do it against the man'.

The text belongs to the so-called Geschwulstbuch ('book of swellings'; Eb 857 (103.19-104.6) to Eb 877 (109.18-110.9)), another larger text group (like the 'Magenbuch'), also consisting of 21 individual texts. The case of the ${ }^{\text {c }}$.t -swelling is closely linked to the whd.w-'Schmerzstoffe' ('pain matter'), which quite probably are its cause. ${ }^{38}$ The afflicted body regions are the acra of the upper extremities, but there is no more detailed specification, i.e. whether the finger tips, the 


\section{6}

palms or the dorsa of the hands are meant. With potentially multiple imaginable cases of this form of $\mathcal{C}^{3} . t$, several or single finger tips or the hands in their entirety could be afflicted. The swelling exudes a rather thin liquid, feels firm when being palpated and is barely or not at all movable. Remarkable here is the explicit warning against injury to the vessel during the prescribed surgical intervention; it implies experience with dangerous bleeding that occurred in previous surgical interventions performed on this body site. The liquid now leaking is more viscous than ante operationem..$^{39}$ The following descriptions imply that the ailment has a disposition to recurrence. The therapeutic goals are intended towards wound closure and necessary haemostatic measures - the circumjacent smaller vessels have been damaged during operation. It is not clear whether the passage $j w=s \check{s} f=s$ $m$-h $h t d r=s$ ('It swells after it has been removed') refers to the disposition to recurrence or to inflammatory changes post operationem. As cause of the ailment jnw.toccurrences are identified, which Ebbell assumes to be 'ungefähr . . Pyaemie, Lymphangit o. ä.', ${ }^{40}$ but adheres to the more indefinite term 'Wandrungen' ${ }^{41}$ (sic) adding the retrospective diagnoses 'Abscess oder Phlegmone'. ${ }^{42}$ Graber-Bailliard proposes to link the case with 'synovite tuberculeuse'. ${ }^{43}$

\section{Sm 10 (5.5-9): unspecific lesion with localisation}

$\check{s}$ S3.w wbnw $m$ tp $n^{5.6} j n h=f$ 'Instruction for a wound at the tip/top of his eyebrow.

$j r h 3 j=k s n w b n w m$ tp $n j n h=f^{c_{r}} n k s$ If you examine a man with a wound in his eyebrow, reaching as far as the bone,

$\underline{d}^{c} r . h r=k w b n w=f$ then you should palpate his wound $n \underline{d r j} n=f k f w . t=f m j d r$ (and) consolidate its gashes for him with a suture,

$5.7 \boldsymbol{d} d . j n=k r=f$ then you must say thereto:

$w b n w \boldsymbol{m} j \boldsymbol{n} h=f$ (one with) a wound in his eyebrow, $\boldsymbol{m h} \boldsymbol{h} \mathbf{j r j}=\boldsymbol{j}$ an ailment which I will treat.

$j r-m-h t j d r=k s w<w t . h r=k s w>h r j w f w 3 \underline{d} h r w$ tpj After you have stitched it, [you should bandage it] with fresh meat on the first day.

jr gmm $=k{ }^{5.8} w b n w$ pn whh jdr.w=f If you find this wound, while its suture has loosened,

$n \underline{d r j} . h r=k n=f m 3 j . w j$ then you should consolidate him its gashes with a pair of bandages,

$s r w h=k s w m m r h . t b j . t r^{\varepsilon} n b r n \underline{d} m=f$ (and) you should treat it with oil/grease and honey every day until he feels better.

(Glosse A) ${ }^{5.9} \mathbf{j r} 3 \mathbf{j} . \boldsymbol{w j} \boldsymbol{n} \boldsymbol{h} \boldsymbol{b s} . \boldsymbol{w}$ As for a pair of bandages from linen, $\check{s}$ sd.wj $p w \boldsymbol{w} \boldsymbol{h} \boldsymbol{h} \boldsymbol{s} . \boldsymbol{w}$ these are two bandages from linen, dd.tw hr sp.tj wbnw $n \mathrm{kft}$ which one applies on the two lips of the gaping wound,

$r$ rdj.t dmj $w^{c} . t r w^{c} . t$ in order to induce that the one sticks to the other'.

The wound described here reaches as far as the bone of the superciliary region. It is debatable whether the inner or outer end of the eyebrow or its widest protrusion is afflicted. 
The bandage with fresh meat occurs 16 times in Papyrus Smith; there exist several interpretative approaches. Herman Grapow speculates regarding a remedy of sympathetic magic. ${ }^{44}$ Liselotte Buchheim essentially sees four purposes: intended suppuration, haemostasis, cooling and maintaining of moisture of the wound. ${ }^{45}$ James Henry Breasted called it the 'favorite remedy for an injury'. ${ }^{46}$ In case the wound suture is loosened, the margins of the wound should be fixed by a supportive bandage. The lacuna containing Gloss B in Sm 2 (1.12-18; here 1.16-17) explicates the 'pair of bandages': 'With regard to a pair of bandages from linen: [These are] two strips of bandage [from linen, which are applied to the gashes of the wound, to induce that one (margin of the wound) sticks] to the other' ${ }^{47}$

\section{Sm 13 (6.3-7): type of lesion with localisation}

$\check{\boldsymbol{s}} \boldsymbol{s} 3 . \boldsymbol{w} \boldsymbol{s} \underline{\boldsymbol{d}} \boldsymbol{m} \boldsymbol{f} \underline{\underline{d}}=f^{\prime}$ 'Instruction for a (splinter-)fracture in his nose.

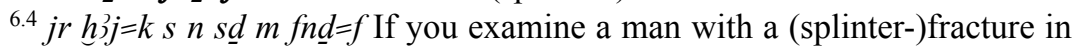
his nose,

$w d j . h r=k^{c}=k h r$ fn $\underline{d}=f$ then you should put your hand on his nose

$m h 3 w s \underline{d}$ f near the fracture,

$n \underline{h} b^{6.5} \underline{h} b=f \underline{h} r \underline{d} b^{c} . w=k$ it shifts under your fingers

jsk $s w h m d j=f$ snf $m \check{s} r . t=f m m s \underline{d} r=f m r\}=f$ and he discharges blood from his nostril, from his ear, from his mouth

$\underline{h} r \underline{d} p f$ because of that fracture

$\left.j w^{6.6} k s n w n=f r\right\}=f \underline{h} r=s$ it is difficult for him to open his mouth as a result of this,

$j w=f d g m$ he is dazed,

$\underline{d} d . j n=k r=f$ then you must say thereto:

$\underline{h} r \mathrm{~s} \underline{d} m$ fnd $=f m h r^{6.7} n j r j . w=n j$ one with a (splinter-)fracture ${ }^{48}$ in his nose, an ailment not to be treated'.

The topic of this text is a severe injury of the nasal region. $\check{s} \underline{d}$ designates a special type of fracture. ${ }^{49}$ During the palpation, the situation or phenomenon $n h b h b$ is noticed. In Papyrus Smith, it occurs four more times, always in the context of the instruction for the palpation. ${ }^{50}$ Breasted translates this word with 'break through' or 'crepitate'; 51 interpretations in the sense of 'to shift' can be found in the works of Ebbell, von Deines, Grapow and Westendorf, as well as Sanchez and Meltzer. ${ }^{52}$ Furthermore, the patient presents unilateral bleedings from multiple sources ( $j s k$ $s w h m d j=f$ snf $m \stackrel{s}{s} r t=f m m s \underline{d} r=f m \quad r \quad=f$ ), difficulties with the opening of the mouth $(j w k s n w n=f r 3=f \underline{h} r=s)$ and dazedness $(j w=f d g m) .{ }^{53}$

\section{Sm 24 (8.22-9.2): group 3 - type of injury with localisation}

This case presents the combination of a 'core diagnosis' and a semeiotics-like specification:

šs3.w $h s b m{ }^{c}$ r.t=f 'Instruction for a fracture in his mandible.

$j r h 3 j=k s n h s b^{8.23} m c_{r . t=f}$ If you examine a man with a fracture in his mandible, 
$w d j . h r=k^{c}=k h r=f$ you should put your hand on him,

$g m m=k h s b$ pf $n h b h b \underline{h} r \underline{d} b^{c} . w=k$ and if you find that fracture shifting under your fingers,

$\underline{d} d . j n=k r=f$ then you must say thereto:

$9.1 \underline{h r j} h s b \boldsymbol{m}^{c} r . t=f$ one with a fracture in his mandible, $\boldsymbol{s} \underline{d} w \boldsymbol{b n} w \boldsymbol{h r}=\boldsymbol{f}$ a wound has opened on it, $w 3 b 3 b . n=f s p$ the discharge (?) has stopped to seep (?), $\check{s} \boldsymbol{m} \boldsymbol{m}=f^{9.2} \underline{h} r=s$ he has a temperature/is febrile as a result of this, $m h r n j r j . w=n j$ an ailment not to be treated'.

The fracture $h s b$ of the viscerocranium, more precisely, of the mandible $c_{r . t}$, is the topic of our last text example. $h s b$ seems to be a fracture of a lesser degree of severity than the one dealt with in Sm $13(-s \underline{d}) .^{54}$ The fracture margins are shiftable when palpated - abnormal motility is a positive sign of the mandibular fracture ${ }^{55}$ It is remarkable that here the actually more detailed semeiotic passage follows the diagnosis - the former is thus not a description of a complicating course of the case.

\section{Conclusion}

The nine texts presented give insights into the Egyptian diagnostic range. As has been demonstrated through the text examples, paraphrases are the dominating type of diagnoses. The frequent occurrence of the diagnosis within the textual structure is remarkable - more important is its essential nature - it is thus a characterising constituent of Egyptian medicine.

\section{Notes}

1 A different version of this chapter was presented under the same title at the BabMed Workshop 'Cultural Systems of Classification: Sickness, Health and Local Biologies. Interdisciplinary Approaches to the Study of Medical Cultures in Anthropology and the Historical Sciences', held 6-7 June 2016 at FU Berlin. This contribution gives insight into the second and third part of Radestock (2015). I want to thank Markham J. Geller and Ulrike Steinert for inviting me to participate in this publication. All translations of passages from Egyptian medical papyri in this chapter are by the author.

2 The editio princeps is by Ebers (1875).

3 Editio princeps by Breasted (1930).

4 Without accession number. Papyrus Ebers has been enrolled for the admission into the UNESCO Memory of the World-Programme.

5 See e.g. Leitz (1989: 23-34); Depuydt (1996: 61-88).

6 In the middle of case 48 verso the text stops abruptly.

7 See in detail Radestock (2015: 279-82); see Pommerening (2017: 167-95) for general remarks on classificatory aspects.

8 See Radestock (2015: 301).

9 Ibid., 297.

10 As a result, the textual format can be classified as 'Lehrtexte mit kasuistischen Merkmalen' (instructional texts with casuistic features); see for further remarks ibid., 129.

11 Ibid., 296-7.

12 Ibid., 297-9. 
13 The rubra of the original are given in bold face within the transliteration.

14 See Radestock (2015) for detailed commentaries on the individual texts of Ebers and Smith presented.

15 Ebbell (1937: 48).

16 Von Deines et al. $(1958:$ IV/1, 89).

17 Westendorf (1999: 579).

18 Bardinet (1995: 277).

19 On colour designations see Schenkel (1963: 131-47, especially 142); Schenkel (2007: 215, 218 and 223); Baines (1985: 282-97); Warburton (2008: especially 230-3, 238, 243 note 143 and 251-2); Warburton (2007: 229-64).

20 See also Erman and Grapow (1957: I, 268, 8).

21 Hannig (2006: 178, italics in the original).

22 On ${ }^{c} k m r w t j$, see Caminos (1972: 251, note 6); Borghouts (1980: 1137-51, especially 1140, note 44 and 1148); Fischer-Elfert (2005: 172-3, note 12 and 175); Grapow (1962: VII/2, 526); Fecht (1958: 36, note 3).

23 Westendorf (1999: 579, notes 38 and 39); his translation is: 'das durch den Mund eingedrungen ist'.

24 Erman and Grapow (1957: V, 352, 26): 'Todeshauch'; comp. Bardinet (1995: 277), who prefers 'c'est un mort qui le parcourt', in other words, the illness is caused by the harmful effect of a dead person.

25 See Hollack and Gahl (2005: 250); they are palpable intestinally as faeces.

26 Westendorf (1999: 580, note 42).

27 Grapow (1962: VII/2, 790), s.v. shn 'Anschwellung; Ballung'.

28 Bardinet (1995: 339). He also understands the preposition in another way: 'autour d'eux', as does Lefebvre (1956: 161).

29 Thus Ebbell (1937: 93): 'small worms (i.e. larvae)'; Bardinet (1995: 339: 'asticots', see also 185 with further explanations); Lefebvre (1956: 161) suggests 'identiques aux petits vers'; note that Von Deines et al. $(1958:$ IV/2, 74) generally reject an identification as worms.

30 Westendorf (1999: 185, see also note 307).

31 Ebbell (1939: 112).

32 Bardinet (1995: 449).

33 Von Deines et al. (1958: IV/2, 205); compare Westendorf (1999: 678).

34 Erman and Grapow (1957: I, 19, 13).

35 Ebbell (1939: 112) is quite sure about the retrospective diagnosis erosio uteri.

36 Dawson (1934: 185-8).

37 See Westendorf (1999: 343-4).

38 For this opinion see for example Bardinet (1995: 370); also Graber-Baillard (1998: 40).

39 Cf. Ebbell (1939: 81-2); Graber-Baillard (1998: 40).

40 Ebbell (1939: 8).

41 Ebbell (1939: 7): 'Wandrungen (sic) der Eiterkrankheit'; the latter is his rendering of $w h d w$.

42 Ebbell (1939: 81-2); cf. Ebbell (1937: 125, note 2); Grapow (1961: VII/1, 57-8), s. v. jnw.t [Krankheitserscheinung] (der Schmerzstoffe).

43 Graber-Baillard (1998: 41).

44 Grapow (1956: 128).

45 Buchheim (1958: 97-116, esp. 99).

46 Breasted (1930: 9).

47 Breasted (1930: 233) sees not only 'ordinary bandages' but 'in reality strips of adhesive tape or plaster' (ibid., 122, 124; cf. Lefebvre 1956: 186, ibid., 180 ad Sm 2; Brawanski 2006: 48).

48 I use the rather colloquial 'splinter' intentionally within the translation; the equivalent in modern nomenclature 'comminuted fracture', is not justified for the translated text.

49 See e.g. Breasted (1930: 262): 'smash . . . comminuted fracture'; rather vague Ebbell (1939: 34): 'Bruch'; Brawanski (2006: 53): 'Splitterbruch', also Westendorf (1999: 
723); Sanchez and Meltzer (2012: 121): 'crushed fracture'. For more details see Radestock (2015: 239-40). See ibid., 240-3, for extensive discussion including the results of several compilers concerning the prepositional referents $f n \underline{d}$, šr.t and $m s d . t$.

50 See for example $\mathrm{Sm} 17$ (7.2).

51 Breasted (1930: 254); cf. also Bardinet (1995: 503).

52 Ebbell (1939: 35); Von Deines et al. (1958: IV/1, 182); Sanchez and Meltzer (2012: 730).

53 See the detailed discussion of these three medical signs in Radestock (2015: 243-5).

54 Ibid., 255.

55 Bechthold et al. (2009: 61).

\section{References}

Baines, J. (1985) 'Color Terminology and Color Classification: Ancient Egyptian Color Terminology and Polychromy', American Anthropologist 87, 282-97.

Bardinet, T. (1995) Les Papyrus médicaux de l'Égypte pharaonique. Paris: Fayard.

Bechthold, H., Hussein, S. and Straubel, U. (2009) 'Schädel-Hirn-Trauma', in Enke, K., Fleming, A., Hündorf, H.-P., Knacke, P. G., Lipp, R. and Lipp, P. (eds.) Lehrbuch für präklinische Notfallmedizin, Band 3, Allgemeine und spezielle Notfallmedizin. Schwerpunkt Traumatologie. Edewecht: Stumpf \& Kossendey, 52-69.

Borghouts, J. F. (1980) 'Magie', in Helck, W. and Westendorf, W. (eds.) Lexikon der Ägyptologie, Vol. III, Horhekenu - Megeb. Wiesbaden: Otto Harrassowitz, 1137-51.

Brawanski, A. (2006) 'Mittelgesichtsverletzungen im Pap. Smith (Fälle 9-14)', Studien zur Altägyptischen Kultur 35, 43-60.

Breasted, J. H. (1930) The Edwin Smith Surgical Papyrus: Published in Facsimile and Hieroglyphic Transliteration with Translation and Commentary. 2 Vol. Chicago: University of Chicago Press.

Buchheim, L. (1958) 'Der “Fleischverband” im alten Ägypten', Sudhoffs Archiv für Geschichte der Medizin 42, 97-116.

Caminos, R. A. (1972) 'Another Hieratic Manuscript from the Library of Pwerem Son of KIIেI', Journal of Egyptian Archaeology 58, 205-24.

Dawson, W. R. (1934) 'Studies in the Egyptian Medical Texts V', Journal of Egyptian Archaeology 20, 185-8.

Depuydt, L. (1996) 'The Function of the Ebers Calendar Concordance', Orientalia 65, 61-88.

Ebbell, B. (1937) The Papyrus Ebers: The Greatest Egyptian Medical Document. Copenhagen: Levin \& Munksgaard.

Ebbell, B. (1939) Die alt-ägyptische Chirurgie. Die chirurgischen Abschnitte der Papyrus E. Smith und Papyrus Ebers. Übersetzt und mit Erläuterungen versehen. Oslo: Det Norske Videnskaps Akademi.

Ebers, G. (1875) Papyros Ebers. Das Hermetische Buch über die Arzneimittel der alten Ägypter in hieratischer Schrift. Herausgegeben, mit Inhaltsangabe und Einleitung versehen, von Georg Ebers. Mit hieroglyphisch-lateinischem Glossar von L. Stern. 2 Vol. Leipzig: Verlag von Wilhelm Engelmann.

Erman, A. and Grapow, H. (eds.) (1957) Wörterbuch der ägyptischen Sprache. 6 Vol. Second edition. Berlin: Akademie-Verlag.

Fecht, G. (1958) Der Habgierige und die Maat in der Lehre des Ptahhoptep (5. und 9. Maxime). Abhandlungen des Deutschen Archäologischen Instituts Kairo 1. Glückstadt/ Hamburg/New York: J. J. Augustin.

Fischer-Elfert, H.-W. (2005) Abseits von Ma'at. Fallstudien zu Außenseitern im Alten Ägypten. Wahrnehmungen und Spuren Altägyptens. Kulturgeschichtliche Beiträge zur Ägyptologie 1. Würzburg: Ergon-Verlag. 
Graber-Baillard, M.-C. (1998) 'Papyrus médicaux de l'Égypte ancienne: Le traité des tumeurs (Pap. Ebers 857 À 877)’, Kyphi. Bulletin du Cercle Lyonnais d'Égyptologie Victor Loret, Lyon 1, 9-61.

Grapow, H. (1956) Kranker, Krankheiten und Arzt. Vom gesunden und kranken Ägypter, von den Krankheiten, vom Arzt und von der ärztlichen Tätigkeit. Grundriß der Medizin der alten Ägypter. Vol. 3. Berlin: Akademie-Verlag.

Grapow, H. (1961) Wörterbuch der medizinischen Texte. Grundri $\beta$ der Medizin der alten Ägypter. Vol. 7/1. Berlin: Akademie-Verlag.

Grapow, H. (1962) Wörterbuch der medizinischen Texte. Grundriß der Medizin der alten Ägypter. Vol. 7/2. Berlin: Akademie-Verlag.

Hannig, R. (2006) Ägyptisches Wörterbuch II. Mittleres Reich und Zweite Zwischenzeit. Part I. Mainz: Philipp von Zabern.

Hollack, K. and Gahl, K. (2005) Auskultation und Perkussion, Inspektion und Palpation. Lehrbuch und Audio-CD mit Auskultationsbeispielen. Fourteenth edition. Stuttgart/New York: Thieme.

Lefebvre, G. (1956) Essai sur la médecine égyptienne de l'époque pharaonique. Paris: Presses Universitaires de France.

Leitz, C. (1989) 'Studien zur ägyptischen Astronomie', Ägyptologische Abhandlungen 49, $23-4$.

Pommerening, T. (2017) 'Classification in Ancient Egyptian Medical Formulae and Its Role in Re-Discovering Comprehensive and Specific Concepts of Drugs and Effects', in Pommering, T. and Bisang, W. (eds.) Classification from Antiquity to Modern Times: Sources, Methods, and Theories from an Interdisciplinary Perspective. Berlin/Boston: de Gruyter, 167-95.

Radestock, S. (2015) Prinzipien der ägyptischen Medizin. Medizinische Lehrtexte der Papyri Ebers und Smith. Eine wissenschaftstheoretische Annäherung. Wahrnehmungen und Spuren Altägyptens. Kulturgeschichtliche Beiträge zur Ägyptologie 4. Würzburg: Ergon-Verlag.

Sanchez, G. M. and Meltzer, E. S. (2012) The Edwin Smith Papyrus: Updated Translation of the Trauma Treatise and Modern Medical Commentaries. Atlanta: Lakewood Books Inc.

Schenkel, W. (1963) 'Die Farben in ägyptischer Kunst und Sprache', Zeitschrift für Ägyptische Sprache und Altertumskunde 88, 131-47.

Schenkel, W. (2007) 'Color Terms in Ancient Egyptian and Coptic', in MacLaury, R. E., Paramei, G. V. and Dedrick, D. (eds.) Anthropology of Color: Interdisciplinary Multilevel Modeling. Amsterdam/Philadelphia: John Benjamins, 211-28.

Von Deines, H., Grapow, H. and Westendorf, W. (1958) Übersetzung der medizinischen Texte; Erläuterungen. Grundriß der Medizin der Alten Ägypter. Vol. 4/1 and 4/2. Berlin: Akademie-Verlag.

Warburton, D. A. (2007) 'Basic Color Terms Evolution in the Light of Ancient Evidence from the Near East', in MacLaury, R. E., Paramei, G. V. and Dedrick, D. (eds.) Anthropology of Color: Interdisciplinary Multilevel Modeling. Amsterdam/Philadelphia: John Benjamins, 229-46.

Warburton, D. A. (2008) 'The Theoretical Implication of Ancient Egyptian Colour Vocabulary for Anthropological and Cognitive Theory', Lingua Aegyptia 16, 213-59.

Westendorf, W. (1999) Handbuch der ägyptischen Medizin. 2 Vol. Handbuch der Orientalistik I/36, 1-2. Leiden/Boston/Köln: Brill. 